\title{
Por uma dimensão comunicativa do consumo
}

For a communicative dimension of consumption

Por una dimensión comunicativa de consumo

Revista Dissertar No32 V.1 ANO XV

DOI: $10.24119 / 16760867$ ed115269

Data de submissão: 19-04-2019

Data de aceite: 01-05-2019

por Suelen de Aguiar Silva ${ }^{1}$

\section{Resumo}

Estudo teórico sobre a sociedade do consumo e a função comunicativa dos bens no sistema social. Os objetivos visam compreender o consumo como uma configuração básica que caracteriza e dá formas às sociedades; tratar sobre as imbricações entre a cultura no consumo e o consumo na cultura, para nos aproximarmos de uma perspectiva sobre a cultura do consumo na modernidade; refletir sobre a produção dos bens, sua função comunicativa e a produção dos gostos na sociedade do consumo. A pesquisa foi baseada em referências bibliográficas. Conclui-se que a função comunicativa na sociedade do consumo se dá em termos de marcação, classificação e distinção social, no uso e na circulação de bens materiais e ou simbólicos que conformam o cotidiano dos sujeitos na sociedade.

Palavras-chave: Cultura. Consumo. Significados. Função comunicativa dos bens.

\begin{abstract}
Theoretical study on the consumer society and the communicative function of goods in the social system. The objectives are to understand consumption as a basic configuration that characterizes and shapes societies; to deal with the imbrications between culture in consumption and consumption in culture, in order to approach a perspective on the culture of consumption in modernity; to reflect on the production of goods, their communicative function and the production of tastes in the consumer society. The research was based on bibliographical
\end{abstract}

1 Suelen de Aguiar Silva: Doutora e mestre pela Universidade Metodista de São Paulo, graduada em Comunicação Social com habilitação em Publicidade e Propaganda pela Universidade Estácio de Sá (2005). Pesquisadora dos processos comunicacionais com foco na comunicação comunitária, alternativa, popular e mídia local. Integrante do Núcleo de Estudos de Comunicação Comunitária e Local (COMUNI) e vicecoordenadora do Grupo de Pesquisa Comunicação para a Cidadania da Intercom. susuaguiar@yahoo.com.br 
references. It is concluded that the communicative function in the society of consumption occurs in terms of marking, classification and social distinction, in the use and circulation of material and symbolic goods that conform the daily life of the subjects in society.

Keywords: Culture. Consumption. Meanings. Communicative function of goods.

\section{Resumen}

Estudio teórico sobre la sociedad del consumo y la función comunicativa de los bienes en el sistema social. Los objetivos apuntan a comprender el consumo como una configuración básica que caracteriza y da formas a las sociedades; tratar sobre las imbricaciones entre la cultura en el consumo y el consumo en la cultura, para acercarnos a una perspectiva sobre la cultura del consumo en la modernidad; reflexionar sobre la producción de los bienes, su función comunicativa y la producción de los gustos en la sociedad del consumo. La investigación se basó en referencias bibliográficas. Se concluye que la función comunicativa en la sociedad del consumo se da en términos de marcación, clasificación y distinción social, en el uso y en la circulación de bienes materiales y / o simbólicos que conforman el cotidiano de los sujetos en la sociedad. Palabras clave: Cultura. Consumo. Significados. Función comunicativa de los bienes

\section{Introdução}

Num mundo dito pós-moderno carregado de imagens, sons, signos, informação, publicidade e do "faça você mesmo", é a busca pela significação e pelo sentido que atribuímos as coisas no cotidiano que faz a roda da vida girar. Desde os primórdios, pelos modos de vestir, de comer, de possuir, de habitar etc. Atualmente, acrescentamos a estes, os aplicativos e widgets em smartphones, tablets, televisores digitais e outras parafernálias tecnológicas. Dos bens materiais aos bens simbólicos, o consumo e os significados que são atribuídos a ele, são frutos de uma construção cultural conformada na vida cotidiana. Significar na acepção estrita da palavra é, ter o sentido de; querer dizer; exprimir, não somente para si, mas para o outro. Nesse sentido, o consumo, em partes, não é uma atividade solitária. O consumo produz significados e ressignifica outros tantos. Adquirir determinada mercadoria em seu objetivo primeiro visa a suprir uma necessidade, desejo ou até mesmo um necejo, mas quando essa mercadoria é consumada, o consumo em sua essência deixa de ser individual para tornar-se coletivo. $\mathrm{O}$ bem adquirido extrapola a produção e circulação de mercadorias e passa a desempenhar uma função comunicativa no mundo social e cotidiano.

Entretanto, quando falamos em consumo, a referência que tão 
logo vem à cabeça é o consumo desenfreado. Aquele capaz de devastar cartões de créditos, de levar sujeitos às ruínas. Pensamos naqueles sujeitos, vide o senso comum, que não tem o que comer, ou vestir, mas fazem uma prestação para ter o produto da moda, que todos estão utilizando, seja um novo produto tecnológico ou mesmo um ingresso para uma partida de futebol. Ah, o consumidor ávido pelo consumo desenfreado é insano e compulsivo. Veja, o pobre está gastando. E o rico, está fazendo o que? As telenovelas destoam à vida real e os jornais influenciam, por vezes, mentem para os consumidores. Será que agem mesmo desta forma ou são apenas reflexo e produto do que é culturalmente construído na sociedade? Em última instância, os gostos e preferências de consumo e as práticas, constitui o sistema social ou o contrário?

Com base em Canclini (2008, p.59), afirmamos que mais do que dar respostas a estas perguntas faz-se necessário discutir a maneira como são formuladas e, acrescentamos, como determinados bens materiais ou simbólicos tornam-se comunicadores e marcadores sociais, fazendo circular mais do que objetos, pessoas. É sobre este questionamento que recai nossa reflexão teórica.

Não temos a pretensão de esgotar o assunto, tampouco de compilar teorias sobre cultura e consumo. Contudo, partimos no intento de desvelar algumas questões que tornam-se premente na atualidade sob o ponto de vista comunicacional. Primeiro, compreender o consumo como uma configuração básica que caracteriza e dá formas às sociedades. Na segunda parte trataremos das imbricações entre a cultura no consumo e o consumo na cultura, para nos aproximamos de uma perspectiva sobre a cultura do consumo na modernidade. $\mathrm{Na}$ última parte a reflexão recai sobre a produção dos bens, sua função comunicativa e a produção dos gostos na sociedade do consumo.

É claro, que é preciso um olhar atento sobre a cultura do consumo e, exatamente por ser tão peculiar e mediadora das relações sociais, é importante estudá-la não somente pelo viés da crítica ao consumo, mas lançando um olhar que permita uma leitura móvel de suas funções e significados sociais. Bem próximo ao que Deleuze e Guatarri (2000, p.32) chamam de rizoma, "um mapa que deve ser produzido, construído, sempre desmontável, conectável, reversível, modificável, com múltiplas entradas e saídas, com suas linhas de fuga". Este artigo teórico será baseado nas contribuições de autores como Mary Douglas e Baron Isherwood $(2004,2007)$, Thorstein Veblen (1983), Grant McCracken (2003), Zygmunt Bauman (2008), Don Slater (2002), Néstor García Canclini (2008) e Pierre Bourdieu (2008).

\section{O consumo em movimento}


O consumo é parte intrínseca das relações humanas e sociais, consumimos para viver e por meio do consumo estabelecemos relações de trocas em várias instâncias. Num primeiro momento o consumo tinha essencialmente um aspecto econômico, baseado em trocas, escambos etc., com o intuito de sobrevivência, na busca por alimentos e suprimentos necessários para a manutenção das ditas sociedades primitivas. O consumo é tão antigo como a própria relação social, antecede a qualquer estudo e rotulação sobre sociedades de consumo e sistemas de produção e circulação de mercadorias. Podemos dizer que numa fase anterior ao iluminismo, por volta do século XVII, o consumo já acontecia entre os pares. Na época dos reinados, por exemplo, os nobres utilizavam seus adornos como as perucas, como forma de marcação cultural, exibição, status e diferenciação social entre as classes. Portanto, o consumo desde sempre existe como forma de subsistência e também como forma de ostentação, porém, os estudos sobre ele são recentes e não há muito consenso sobre quando deixaram de responder somente as necessidades essenciais à manutenção da vida humana para passar a ter outros significados e sentidos.

Thorstein Veblen (1983, p.37) afirma que durante os primeiros estágios do desenvolvimento econômico, "o consumo ilimitado de bens, especialmente dos bens de maior excelência, e como regra qualquer consumo que exceda o mínimo necessário à subsistência, pertence normalmente à classe ociosa". Veblen propõe uma teoria econômica das classes ociosas, observando o consumo conspícuo e o sistema de preferências dessas classes. O consumo passa então a ser delineado não somente pelo o seu valor de subsistência, mas pelo seu caráter excedente e principalmente como forma de marcação de diferenças entre classes e estilos de vida. Na visão de Veblen (1983), o consumo passa a representar não somente a satisfação de necessidades básicas. Sob um ponto de vista moralizante relaciona o mundo dos bens materiais à banalidade, ao supérfluo. Pelo viés do consumo a racionalidade humana no jogo da emulação cede lugar à irracionalidade, numa busca constante por status e pelo desejo em possuir bens de outras classes ou até mesmo de ser incluídos nelas.

Falar sobre consumo é pisar num terreno arenoso, muitas visões buscaram e buscam dar sentido e função a ele. O consumo pode ser pensado como vimos em Veblen (1983), a partir da perspectiva moralista, no qual é o tom denunciatório e crítico ao consumo o seu ponto fundante. Tem-se a perspectiva naturalista, que visa a atender as necessidades físicas e racionais dos consumidores, bem como suas necessidades emocionais e psicológicas. Tem-se ainda a função hedonista, hoje pautada pela mídia, na qual a função do consumo visa a garantir a felicidade, por meio da posse de bens materiais e simbólicos, até a segunda ordem. A felicidade é o algoz e o amigo do 
consumo, por meio da publicidade, do marketing e das mais variadas e novas formas de comunicação, produtos e serviços visam à satisfação dos consumidores, corpórea e simbolicamente. Neste terreno arenoso, nascem juntos o consumidor e a sociedade do consumo. E é por esta, por seus contornos, funções e vieses que elucidamos o mundo dos bens, no qual circulam mais do que objetos e marcas, mas pessoas.

\section{Teoria informativa sobre os bens de consumo}

O mundo dos bens 40 anos após as contribuições de Mary Douglas e Baron Isherwood parece se reinventar. Principalmente se considerarmos que os diversos teóricos que pesquisam o consumo têm focos bem diferentes e que o assunto vem sendo estudado por várias perspectivas como a filosófica, a sociológica e a econômica. Vários autores, já citados na introdução, buscam por uma explicação que dê conta do consumo em distintos aspectos, desde a produção à circulação de bens. Diferentemente dos demais críticos que viam no consumo uma forma de alienação, a perspectiva de Douglas e Isherwood é inovadora.

As pistas que o clássico livro "O Mundo dos Bens" nos deixou é mais do que buscar uma teoria que abarque as instâncias do consumo, mas sim refletir e buscar uma teoria informativa que perpasse a reprodução social, enxergando o consumo a partir da perspectiva cultural, ou seja, dos significados sociais dos bens, entendendo-os como signos. E mais do que objetos, a investigação recai sobre a circulação das pessoas neste mundo dos bens, como aponta Mary Douglas (2007, p.30), em "O mundo dos bens, 20 anos depois". Um longo percurso no campo da antropologia e da economia precisou ser seguido para que os autores chegassem à base teórica de uma antropologia do consumo. Todavia, é crucial entender que esta proposição ocorre na relação entre cultura e consumo como sistema social. E que os bens de consumo têm uma significação que vai além do seu aspecto comercial e utilitário, conforme aponta McCracken (2003, p.99), apoiado em Douglas e Isherwood, "esta significação consiste largamente em sua habilidade em carregar e em comunicar significado cultural". Haja vista, a importância do consumo se dá pela sua unidade em nosso cotidiano por meio da estruturação de valores que constroem e conformam identidades, bem como medeiam relações sociais.

Para uma determinada linha e tradição marxista o grande foco do consumo estava no sistema de produção. O que estrutura determinada sociedade é o modo de produção e os fatos sociais comprovam como é estruturante e importante este tipo de sistema para uma sociedade. Já numa perspectiva mais contemporânea passa-se a analisar como se dá o processo inverso. Na perspectiva clássica que 
marcou a primeira metade do século XX com foco na produção, a única coisa que sobrava para o consumo era basicamente a reprodução social. Haveria uma lógica interna ao sistema e essa lógica seria emanada da produção e os bens ao circular pela sociedade iriam reforçar em cada uma das esferas, na da circulação, na da produção e, na do consumo, os aspectos inerentes à reprodução social. $\mathrm{O}$ aspecto de reprodução do sistema estaria muito marcado no consumo.

Douglas e Isherwood (2004) não vão se opor a este fato, mais buscam o entendimento de como o consumo parte de uma lógica que não é somente da racionalidade econômica, mas também sociocultural. Portanto, cada indivíduo livre é responsável pela exclusividade de sua casa, pela alocação de seu tempo livre e pela sua hospitalidade, reiteram os autores. A questão que torna-se premente é a do envolvimento social e não necessariamente no tocante a pobreza e a riqueza, mas o quanto de envolvimento o indivíduo tem em sua rede de relacionamento que possa aumentar a sua comunicação. Os bens incluídos nesse sistema social servem como marcadores significativos e seus usos sociais espelham as práticas de cada indivíduo, reforçando o "eu" por meio de suas conexões e do sistema de informação gerado a partir do outro. $\mathrm{O}$ consumo na modernidade está associado à emergência do eu. Ao mesmo tempo em que consumimos individualmente, consumimos coletivamente, por exemplo, a roupa que vestimos para determinada ocasião está mediada por fatores que vão determinar a escolha. $\mathrm{O}$ consumidor é um animal social, esclarece Douglas (2007, p.23) "o consumidor não quer objetos para ele mesmo, mas para dividir, dar, e não só dentro da família", essa passagem refuta a ideia de uma teorização econômica que coloca o comprador como o usufruidor do bem adquirido, de forma privada ou familiar. Exatamente porque a esfera de circulação do consumo ocorre sempre na relação com o outro.

\section{Localizando a cultura no consumo e o consumo na cultura}

A racionalização que se dá com ênfase no indivíduo, consequentemente com a morte de "Deus" e da religião caracteriza o próprio momento da era moderna. Passa-se a centrar mais na razão, no seu conhecimento, do que na palavra de Deus. Na medida em que passa-se a explicar o mundo pela razão, ela é do indivíduo, e este passa a ser o centro. Então, esse indivíduo vai ter a capacidade de gerenciar o seu consumo, porque gerenciar o seu consumo é agir dentro da cultura. Neste sentido, recorremos ao sociólogo americano Don Slater (2002) que também coloca na pauta dos estudos sobre consumo a própria dimensão da cultura. Em sua obra faz um grande balanço sobre as teorias críticas do consumo que demanda conhecimento de autores importantes como Marx, Debord, Baudrillard na perspectiva 
do consumo, Stuart Hall com a construção de identidades e até mesmo Foucault, com as técnicas e cuidados de si.

Don Slater (2002, p.18) afirma que a cultura do consumo não é recente, como bem já mencionamos, mas está vinculada à modernidade como um todo. As instituições, infraestruturas e práticas essenciais da cultura do consumo tiveram origem no início do período moderno e para algumas classes e setores econômicos algumas delas estavam estabelecidas na época. Slater (2002, p.18) diz que a cultura do consumo não é uma consequência tardia da modernização industrial e da modernidade cultural, mas sim parte da própria construção do mundo moderno.

No entanto, Slater (2002) diferencia cultura do consumo e cultura de consumo, importante colocação para verificarmos como se conforma o consumo na contemporaneidade. Para o sociólogo, quando fala-se cultura do consumo está afirmando que existe um tipo de manifestação cultural que faz com que as sociedades sejam totalmente mediadas pelo consumo, ou seja, as relações sociais passam por essa mediação. Já quando se fala em cultura de consumo, fala-se em momentos específicos e práticas específicas que se associam ao consumo, como por exemplo, o ato de compra, quando assistimos a TV, quando vamos ao cinema etc. "A noção de cultura do consumo implica que no mundo moderno as práticas sociais, os valores culturais, ideias são definidos e orientados pelo consumo" (SLATER, 2002, p.32).

A cultura do consumo marca a modernidade e é anterior a revolução industrial, segundo Slater (2002), podendo ser localizada a partir do século XVIII, pós-iluminismo. A própria construção do eu na modernidade, da noção de liberdade, é propício da cultura do consumo. É como a própria construção do romantismo, do eu interior, da pulsão, dos desejos. O consumo nesse sentido parece ser do reino da vontade e não dá necessidade. A cultura do consumo se expandiu de tal forma que a própria cultura é o consumo. Não é só a satisfação do objeto, mas além disso é a conformação das identidades por meio do ato de consumir. Isso configura a nossa identidade, nos qualifica, de certa forma podemos arriscar em dizer que o consumo colonizou a cultura. Em Slater (2002, p.67) para grande parte do pensamento ocidental moderno a cultura do consumo é vista como um oximoro, dois termos contraditórios unidos pela modernidade, cuja desregulamentação social leva a uma crise de identidade. E é pelas vias do consumo que o sujeito escolhe sua identidade e se identifica, não mais pelas vias de uma ordem social instável.

O sociólogo polonês, crítico mordaz da sociedade do consumo, Zygmunt Bauman (1998) esclarece este assunto em "O Mal estar da PósModernidade". Como aponta Bauman, na modernidade as identidades eram projetadas para serem rígidas, com o projeto de construção 
de uma identidade nacional ligado ao Estado, a fim de diminuir as diferenças existentes na sociedade. Agora, essas mesmas identidades precisam ser fluídas e frouxas, pois seguem a lógica do mercado, visto que há o esfacelamento do Estado. Aquele que era o regulador da ordem, da vida cotidiana e que ditava às normas, por meio do estado de bem estar social. Hoje prima-se pela desregulamentação, pois existe uma outra ética, a do mercado.

Passamos da sociedade dos produtores para a sociedade dos consumidores e, segundo Bauman, se antes a primazia era em busca da segurança, hoje a primazia é em busca da liberdade em detrimento da segurança. Já não existe uma estabilidade, pois cresce a busca por novas experiências e sensações. Se antes a liberdade era concedida pelo Estado, ele legislava a ordem. Hoje, o Estado legisla para o bom funcionamento do mercado e a liberdade é adquirida junto com um quinhão de incertezas. Já não se pode mais contar com o estado de bem estar social. Cada um é responsável por suas escolhas. Por isso a identidade dos sujeitos tende a ser flexível, apenas uma identidade não dá, temos de ser várias coisas ao mesmo tempo. Essa é a identidade que se ajusta ao mundo em que a arte de esquecer é um bem mais importante que arte de lembrar, uma identidade de palimpsesto (BAUMAN, 1998, p.36). “O mundo pós-moderno está se preparando para a vida sob uma condição de incerteza que é permanente e irredutível", alude Bauman (1998, p.32).

Voltando à questão de Slater (2002), ele apresenta duas perspectivas para pensar a relação entre cultura do consumo e a modernidade. A primeira é a perspectiva produtivista - antes de consumir é preciso produzir. Era preciso haver a industrialização para que houvesse o consumo. Num primeiro momento, precisou haver a revolução industrial na Inglaterra no meio do século XVIII para depois haver a revolução do consumo. Daí quando o consumo passa a mediar as relações é que se pode falar em cultura do consumo. Exatamente quando não é só mais um momento específico, quando não é apenas mais um ato de compra. A segunda é a perspectiva revisionista - que vai afirmar que a revolução do consumo antecede a revolução industrial. Antes da revolução industrial, já havia um conjunto de condições do próprio consumidor como por exemplo, a circulação de mercadorias (SLATER, 2002, p.25).

De forma geral a cultura do consumo é associada à sociedade dita pós-moderna, como se a partir de década de 1980 a sociedade tivesse passado por um tipo de configuração que permitiu que a cultura fosse baseada no consumo. A esse respeito Slater afirma (2002, p.19) que,

A década de 1980 assistiu a uma das mais incríveis 
redescobertas do consumismo. O consumidor era o herói do momento, não apenas como provedor do poder aquisitivo que serviria como combustível para o crescimento econômico (embora este também fosse fundamental, e encorajado pela expansão fenomenal do crédito, pelo financiamento do déficit e por reduções no imposto de renda, mas como o próprio modelo do sujeito e cidadão moderno. Inspirada no neoliberalismo - especificamente na economia Reagan e no thatcherismo - a opção do consumidor tornou-se o modelo obrigatório para todas as relações sociais e exemplo de dinamismo e liberdade cívicos.

Outro ponto importante sobre a década de 1980 é que nela também se anunciou a subordinação da produção ao consumo sob a forma de marketing, tais como "o design, a venda no varejo, a publicidade e o conceito de produto estavam em ascensão, retratados na teoria pós-moderna como o triunfo do signo e o embelezamento da vida cotidiana" (SLATER, 2002, p.19). Assim como as características do consumo mudam com o tempo, as formas de encará-lo também.

O consumo é sempre e em todo lugar um processo cultural, mas "cultura do consumo" é singular e específica: é o modo dominante de reprodução cultural desenvolvido no Ocidente durante a modernidade. A cultura do consumo é, em aspectos importantes, a cultura do Ocidente moderno - crucial, certamente, para a prática significativa da vida cotidiana no mundo moderno; e, num sentido mais genérico, está ligada a valores, práticas e instituições fundamentais que definem a modernidade ocidental, como a opção, o individualismo e as relações de mercado (SLATER, 2002, p.17).

Para Slater se tivéssemos de isolar uma única característica definidora sobre a cultura do consumo, seria o seguinte, ela "designa um acordo social onde a relação entre a cultura vivida e os recursos sociais, entre modos de vida significativos e os recursos materiais e simbólicos dos quais dependem, são mediados pelos mercados" (SLATER, 2002, p.17). Portanto, a cultura do consumo é definidora de um sistema em que o consumo é dominado pelo consumo de mercadorias, e onde a reprodução cultural pode ser compreendida como algo a ser realizado por meio do exercício do livre-arbítrio pessoal na esfera privada da vida cotidiana.

Voltamos então à questão da característica definidora sobre 
a sociedade do consumo. Pelas vias do liberalismo, a sociedade do consumo parece produzir um consumidor herói e um consumidor idiota (SLATER, 2002, p.64), mas dotado de livre-arbítrio para escolher nos mercados, contraditório não? O interesse fundamental do liberalismo não diz respeito à sua liberdade e a sua autonomia, mas em produzir indivíduos capazes de se autogovernar ou de se autoadministrar (SLATER, 2002, p.65). Para finalizar, "o consumidor é a síntese do indivíduo liberal, e o consumismo pode ser visto como um campo de treinamento social preeminente em sua produção ética" (SLATER, 2002, p.66). Em Foucault (2006), tonar-se o indivíduo que escolhe não é uma liberação, mas sim uma estratégia da moderna arte de governar.

[...] aquilo a que o governo se refere é não um território e sim um conjunto de homens e coisas. Estas coisas, de que o governo deve se encarregar, são os homens, mas em suas relações com coisas que são riquezas, os recursos, os meios de subsistência, o território em suas fronteiras, com suas qualidades, clima, seca, fertilidade, etc.; os homens em suas relações com outras coisas que são os costumes, os hábitos, as formas de agir ou de pensar, etc.; [...] (FOUCAULT, 2006, p.282).

Seja herói ou idiota, empreendedor ou soberano o consumidor precisa criar e manter relações sociais, com pessoas, com mercadorias materiais e simbólicas, em última instância mediada pelo mercado. É na vida cotidiana que a cultura comparece e a cultura do consumo, por sua vez, tornou-se ponte para a mediação das relações estabelecidas entre grupos, comunidades, tribos etc. Mais do que gerenciar o consumo o que faz a cultura é gerenciar as práticas sociais e a disposição para a aquisição de bens, principalmente pelo caráter comunicativo que ela representa tanto nos aspectos de reprodução social quanto nos aspectos relacionados à conformação identitária num mundo marcado por bens.

\section{A função comunicativa dos bens na sociedade do consumo}

Nessa parte o foco da análise incide sobre a produção dos bens, sua função comunicativa e a produção dos gostos na sociedade do consumo. O intuito é correlacionar as três assertivas ao complexo sistema social que os constitui e que é constituinte de suas práticas sociais e disposições para o consumo. Os bens podem ser entendidos como parte constituinte de um sistema de informação, pois os objetos que um sujeito adquiri e ostenta não estão relacionados apenas ao 
status, mas às práticas sociais, aos interesses e aos gostos de quem os possui. Douglas e Isherwood (2009) destacam que os bens de consumo não são meras mensagens; eles constituem o próprio sistema. "Os bens são neutros, seus usos são sociais, podem ser usados como cerca ou como pontes" (2009, p. 36). Ou seja, os usos sociais que fazemos dos bens são determinantes para entender as especificidades das relações sociais.

Por sua vez, o sociólogo francês Pierre Bourdieu $(2008$, p.9) fala sobre a existência de uma economia dos bens culturais, que o gosto é um marcador de classe e que o consumo de bens preenche uma função social que legitima diferenças sociais. Mary Douglas tem a mesma abordagem de Bourdieu, porém, é interessante que em "A Distinção" Bourdieu não só teoriza sobre esses aspectos como a antropóloga, mas faz uma teoria da prática, aplicando sua metodologia de pesquisa em qualquer objeto, por meio das práticas culturais, seja na frequência de museus, concertos, exposições, leitura, modos de vestir, de comer, de cortar o cabelo, entre outros. De modo que, a observação científica empreendida por Bourdieu em suas variadas pesquisas demonstra que as necessidades culturais são o produto da própria educação.

Bourdieu (2008) cria uma teoria materialista para pensar a questão da cultura, através de seus conceitos principais como habitus, prática e campo. De forma geral, porém atenta, a ideia de chamá-lo para a discussão é justamente trazer à baila sua teoria da prática sobre as formas de distinção social no cotidiano. A ideia central da distinção é que o consumo cultural, classifica e distingue as pessoas por sua classe social. Ou seja, a distinção é um processo pelo qual as lutas simbólicas estruturam nossa sociedade e que o campo da cultura está estruturado homologamente a um campo social.

O princípio da homologia funcional e estrutural segundo Bourdieu (2008, p.217) é que a lógica do campo de produção e a lógica do campo de consumo são objetivamente orquestradas residindo no fato de que, por um lado todos os campos especializados, como a alta costura, a pintura, o teatro etc. tendem a se organizar segundo a mesma lógica. Em outras palavras, o acordo estabelecido entre classes de produtos e classes de consumidores só é realizada no consumo por intermédio da homologia entre bens e grupos definidores do gosto. Afirma Bourdieu (2008, p.217),

ao proceder a uma escolha segundo seus gostos, o indivíduo opera a identificação de bens objetivamente adequados à sua posição e ajustados entre si por estarem situados em posições sumariamente equivalente a seus respectivos espaços - filmes ou peças de teatro, histórias em quadrinhos ou romances, mobiliário ou vestuário - 
ajudado, neste aspecto, por instituições, butiques, teatros [...], críticos, jornais e semanários, escolhidos, aliás, segundo o mesmo princípio; além disso, por serem definidas por sua posição em um campo, elas próprias devem ser objeto de uma identificação distintiva.

Todavia, parece nos adequado reforçar que o gosto assume aí um importante marcador de classes e que reforça as diferenças sociais. Ou seja, a distinção ocorre mediante a luta entre classes , frações de classes, grupos específicos dentro de um determinado campo. Importante também é frisar que a maneira pelo qual o capital econômico, simbólico, cultural se estabelece é conformando a divisão das pessoas em classes e ou grupos, que consequentemente produz o habitus, como elemento central de cognição do indivíduo dentro da sociedade e pela forma como este indivíduo atua na reprodução social.

Para Bourdieu (2008, p.162), o habitus é, com efeito, princípio gerador de práticas objetivamente classificáveis e, ao mesmo tempo, sistema de classificação de tais práticas. $\mathrm{O}$ habitus se inscreve no corpo, na pele e está arraigado na maneira com atuamos na vida cotidiana. É a forma pela qual agimos, andamos, conformamos nosso corpo, como nos comportamos na trivialidade do cotidiano e em situações sociais que demandam comportamentos diferenciados, que vai mudando ao longo do tempo e de acordo com o momento histórico.

Para Bourdieu (2008, p.162) a "capacidade de produzir práticas e obras classificáveis, além da capacidade de diferenciar e de apreciar essas práticas e esses produtos (gosto), é que se constitui o mundo social representado, ou seja, o espaço dos estilos de vida", nesta relação o habitus é definido. Bourdieu (2008, p.183) diz que o corpo como portador de sinais é também um produtor de signos. Esses sinais corpóreos, digamos, são frutos de uma fabricação cultural, cujo efeito primeiro serve para marcar as diferenças entre classes no que diz respeito a cultura e a forma que a consomem. A maneira de posicionar a boca ao falar ou de assentar a voz, até mesmo a valorização da virilidade pode ser determinante para incluir determinada pessoa numa classe ou fração de classe social. Tais maneiras servem como marcadores de classes, e a sua vez, funcionam como comunicadores sociais. Reside nesta afirmação o caráter simbólico que os bens e as disposições (talentos, aptidões, capitais) possuem ao utilizá-los, reproduzindo a estrutura do espaço social.

Contudo, essas questões de estilo de vida e de gosto só podem ser observadas quando comparadas ao outro. "[...] $\mathrm{O}$ fato de comer nos conformes é, por exemplo, a maneira de prestar homenagem aos anfitriões e à dona da casa" (BOURDIEU, 2008, p.187). Neste aspecto a comida serve como ponte para uma cerimônia social. Comer como um 
glutão ou como uma pessoa requintada? No exemplo acima, a forma e a função estética se sobressaem em relação à função primária, de se alimentar para saciar a fome.

Na mesma linha, Don Slater (2002, p.149) reflete a partir de Mary Douglas e Baron Isherwood que o consumo se insere em um campo social de práticas.

O consumo enquanto fluxo de informações integra as pessoas num mundo social inteligível. Conhecimento dos códigos de consumo e participação nos rituais de consumo são essenciais para o 'projeto de criar inteligibilidade' e conseguir que seja socialmente confirmado: o indivíduo usa o consumo para dizer algo sobre si mesmo, de sua família, do lugar onde vive...Os tipos de afirmações que ele faz dizem respeito ao tipo de universo em que está (SLATER, 2002, p.149).

No entanto, Slater acredita que esta afirmação se for colocada inversamente pode gerar uma situação de desigualdade, já que a pobreza, assim como em Mary Douglas (2004) não é ausência de riqueza e sim exclusão na participação no fluxo de informações. Ou seja, "ao consumir menos somos excluídos de eventos e conhecimentos sociais fundamentais" explana Slater (2002, p.149). A visão de Slater pode ser mais bem vislumbrada em Bourdieu (2008, p.9) quando esclarece que as maneiras de adquirir sobrevivem na maneira de utilizar as aquisições, pois "a atenção prestada às maneiras tem sua explicação se observarmos que, por meio destes imponderáveis da prática, são reconhecidos os diferentes modos de aquisição". Corrobora ele,

Sabendo que a maneira é uma manifestação simbólica, cujo sentido e valor dependem tanto daqueles que a percebem quanto daquele que a produz, compreende-se que a maneira de usar bens simbólicos e, em particular, daqueles que são considerados como os atributos da excelência, constitui um dos marcadores privilegiados da "classe" [...] (BOURDIEU, 2008, p.65).

Detidamente, voltando à questão sobre os bens culturais e a produção dos gostos em Bourdieu (2008, p.56), “o gosto é o princípio de tudo o que se tem, pessoas e coisas, e de tudo o que se é para os outros, daquilo que serve de base para se classificar a si mesmo e pelo qual é classificado". As preferências manifestas, os gostos, são a afirmação prática de uma diferença inevitável. "[...] os gostos são, antes de tudo, aversão, feita de horror ou de intolerância visceral ("dá ânsia 
de vomitar"), aos outros gostos, aos gostos dos outros", diz Bourdieu (2008, p.56). Permanece então, a máxima de que gosto não se discute, se pratica, servindo para a manutenção do espaço social culturalmente constituído no cotidiano.

\section{Considerações}

Se aproximarmos a análise teórica de Veblen à teoria da prática desenvolvida pelo sociólogo Pierre Bourdieu em suas pesquisas sobre a distinção social, correlacionando-a com a antropologia do consumo de Mary Douglas e Baron Isherwood, e de Don Slater, com a cultura do consumo, podemos arriscar a seguinte contestação - a função comunicativa na sociedade do consumo se dá em termos de marcação, classificação e distinção social, no uso e na circulação de bens materiais e ou simbólicos que conformam o cotidiano dos sujeitos na sociedade. Da mesma forma, a sociedade de consumidores precedida pela sociedade de produtores, aludida por Bauman (2008), repleta de consumidores ávidos e consumidores falhos, pode ganhar um caráter comunicativo, se lançarmos um olhar além da produção e circulação de bens. Localizando o consumo como parte fundamental do cotidiano socialmente constituído pela cultura, como estrutura estruturada e estruturante da sociedade (BOURDIEU, 2008), formada pelos próprios produtores e consumidores.

$\mathrm{Na}$ medida em que os bens circulam nesta sociedade fazem muito mais do que serem simples receptáculos ou transferidores de símbolos e significados, pois as mercadorias e os bens simbólicos servem antes de mais nada, como forma de pertencimento e marcação cultural dentro de determinado território. A contribuição crítica de Bauman (2008, p.109) sobre a sociedade de consumo, abre uma alternativa para se pensar o consumo no bojo dos processos culturais que constituem os sujeitos, como seres dotados de subjetividades. Quando ele reconhece mesmo que de forma crítica, que os bens servem para mobilizar outras pessoas, parafraseando a antropóloga Mary Douglas.

Muitas são as abordagens para tratar do tão conflituoso par, cultura e consumo. Desde as marxistas que visam à produção e circulação de bens e mercadorias na sociedade, às clássicas e também contemporâneas, que visam a incluir a cultura de consumo como parte integrante e constituinte da nossa sociedade. Teorias no âmbito da econômica, da antropologia, dos estudos culturais e mais recentemente no da própria comunicação. Umas mais críticas quanto a esta configuração e dimensão cultural que tomou o consumo no cotidiano dos sujeitos a partir do advento da revolução industrial que tece, inclusive, críticas severas quanto ao ato de consumo e que este gera a atomização, individualização e alienação dos sujeitos. E outras, 
visando mais ao aspecto cultural e inclusivo, por meio de estudos que visam à educação para o consumo, por exemplo. E ainda, como uma das dimensões de cidadania ou como produto de entretenimento midiático.

Entretanto, o consumo exerce uma função comunicativa tão poderosa que marca e imprime um estilo de vida. Não temos como fugir da sociedade do consumo, aliás, não queremos, pois ela atravessa nosso cotidiano e está imbricada nas instâncias mais peculiares da vida. A sociedade do consumo nos constitui como sujeitos que se comunicam por meio de seus bens sejam eles materiais ou simbólicos e a constituímos como sistema social. Como um autogoverno, de si e do outro, numa constante imbricação entre coisas e homens, ou melhor, entre bens e pessoas. Assim como na metáfora do navio citada por Foucault (2002, p.283), “O que é governar um navio? É certamente se ocupar dos marinheiros, da nau e da carga; governar um navio é também prestar atenção aos ventos, aos recifes, às tempestades, às intempéries". O território e a propriedade são variáveis, o essencial é portanto esse conjunto de coisas e homens que dão sentido a sociedade do consumo.

\section{Referências}

BAUDRILLARD, Jean. A sociedade de consumo. Lisboa: Edições 70, 1991.

BAUMAN, Zygmunt. O Mal-Estar da Pós-Modernidade. Rio de Janeiro: Zahar, 1998.

BAUMAN, Zygmunt. Vida para consumo: a transformação das pessoas em mercadoria. Rio de Janeiro: Zahar, 2007.

BOURDIEU, Pierre. A Distinção. Crítica social do julgamento, São Paulo: Edusp, 2008.

CAMPBELL, Colin. Ética Romântica e o Espírito do Consumismo Moderno. Rocco, 2001.

CANCLINI, Néstor García. Diferentes, desiguais e desconectados. Mapas da interculturalidade. Rio de janeiro: Ed. UFRJ, 2009.

CANCLINI, Néstor García. Consumidores e Cidadãos. Conflitos multiculturais da globalização. 7.ed. Rio de janeiro: Ed. UFRJ, 2008. 
DELEUZE, Gilles; GUATTARI, Félix. Mil Platôs: capitalismo e esquizofrenia. vol.1. São Paulo: Ed.34, 2000.

DOUGLAS, Mary. O mundo dos bens, vinte anos depois. Horiz. antropol. [online]. 2007, vol.13, n.28, pp. 17-32. Disponível em http://www.scielo.br/scielo.php?script=sci_arttext\&pid $=$ S0104-71832007000200002

Acesso em: 14 de jan. de 2014.

DOUGLAS, Mary; ISHERWOOD, Baron. O Mundo dos Bens: para uma antropologia do consumo. Rio de Janeiro: Editora UFRJ, 2004.

FOUCAULT, Michel. Microfísica do Poder. 22 ed. Rio de Janeiro: Graal, 2006.

HALL, Stuart. A identidade cultural na pós-modernidade. Rio de Janeiro: Ed. DP\&A, 2005.

MCCRACKEN, Grant. Cultura e consumo: novas abordagens ao caráter simbólico dos bens e das atividades de consumo. Tradução de Fernanda Eugenio. Rio de Janeiro: Mauad, 2003.

ORTIZ, Renato (org.). Bourdieu - Sociologia. vol. 39. São Paulo: Ática. Coleção Grandes Cientistas Sociais, 1983.

SCHWERINER, Mário Ernesto René. Comportamento do consumidor: identificando necejos e supérfluos essenciais. São Paulo: Saraiva, 2006.

SLATER, Don. Cultura do Consumo e Modernidade. São Paulo: Nobel, 2002.

VEBLEN, Thorstein. A teoria da classe ociosa: um estudo econômico das instituições. São Paulo: Nova Cultural, 1983. 
RDISSHRTARDISSERTARDISSERTARDISSHRTARDISSERTARDISSERTARDISK

TARDISSERTARDISSERTARDISSERTARDISSERTARDISSERTARDISSERTARD HRTARDISSERTARDISSERTARDISSERTARDISSERTARDISSERTARDISSERTA] SSERTARDISSERTARDISSERTARDISSERTARDISSERTARDISSERTARDISSER RDISSERTARDISSERTARDISSERTARDISSERTARDISSERTARDISSERTARDISE TARDISSERTARDISSERTARDISSERTARDISSERTARDISSERTARDISSERTARD HRTARDISSERTARDISSERTARDISSERTARDISSERTARDISSERTARDISSERTA SSERTARDISSERTARDISSERTARDISSERTARDISSERTARDISSERTARDISSER RDISSERTARDISSERTARDISSERTARDISSERTARDISSERTARDISSERTARDISC TARDISSERTARDISSERTARDISSERTARDISSERTARDISSERTARDISSERTARD HRTARDISSERTARDISSERTARDISSERTARDISSERTARDISSERTARDISSERTA] SSERTARDISSERTARDISSERTARDISSERTARDISSERTARDISSERTARDISSER RDISSERTARDISSERTARDISSERTARDISSERTARDISSERTARDISSERTARDISE IARDISSERTARDISSERTARDISSERTARDISSERTARDISSERTARDISSERTARD RTARDISSERTARDISSERTARDISSERTARDISSERTARDISSERTARDISSERTA] SSERTARDISSERTARDISSERTARDISSERTARDISSERTARDISSERTARDISSER RDISSERTARDISSERTARDISSERTARDISSERTARDISSERTARDISSERTARDISC TARDISSERTARDISSERTARDISSERTARDISSERTARDISSERTARDISSERTARD HTARDISSERTARDISSERTARDISSERTARDISSERTARDISSERTARDISSERTA] SSERTARDISSERTARDISSERTARDISSERTARDISSERTARDISSERTARDISSER RDISSERTARDISSERTARDISSERTARDISSERTARDISSERTARDISSERTARDISE TARDISSERTARDISSERTARDISSERTARDISSERTARDISSERTARDISSERTARD HRTARDISSERTARDISSERTARDISSERTARDISSERTARDISSERTARDISSERTA] SSERTARDISSERTARDISSERTARDISSERTARDISSERTARDISSERTARDISSER RDISSERTARDISSERTARDISSERTARDISSERTARDISSERTARDISSERTARDISE TARDISSERTARDISSERTARDISSERTARDISSERTARDISSERTARDISSERTARD HRTARDISSERTARDISSERTARDISSERTARDISSERTARDISSERTARDISSERTA] SSERTARDISSERTARDISSERTARDISSERTARDISSERTARDISSERTARDISSER RDISSERTARDISSERTARDISSERTARDISSERTARDISSERTARDISSERTARDISC ГARDISSERTARDISSERTARDISSERTARDISSERTARDISSERTARDISSERTARD RTARDISSERTARDISSERTARDISSERTARDISSERTARDISSERTARDISSERTA] SSERTARDISSERTARDISSERTARDISSERTARDISSERTARDISSERTARDISSER RDISSERTARDISSERTARDISSERTARDISSERTARDISSERTARDISSERTARDISC TARDISSERTARDISSERTARDISSERTARDISSERTARDISSERTARDISSERTARD HRTARDISSERTARDISSERTARDISSERTARDISSERTARDISSERTARDISSERTA] SSERTARDISSERTARDISSERTARDISSERTARDISSERTARDISSERTARDISSER RDISSERTARDISSERTARDISSERTARDISSERTARDISSERTARDISSERTARDISE IARDISSERTARDISSERTARDISSERTARDISSERTARDISSERTARDISSERTARD HRTARDISSERTARDISSERTARDISSERTARDISSERTARDISSERTARDISSERTA] SSERTARDISSERTARDISSERTARDISSERTARDISSERTARDISSERTARDISSER RDISSERTARDISSERTARDISSERTARDISSERTARDISSERTARDISSERTARDISE TARDISSERTARDISSERTARDISSERTARDISSERTARDISSERTARDISSERTARD HRTARDISSERTARDISSERTARRTARDISSERTARDISSERTARDISSERTARDISS IARDISSERTARDISSERTARDISSERTARDISSERTARDISSERTARRTARDISSER RDISSERTARDISSERTARDISSERTARDISSERTARDISSERTARDISSERTARDISE 
RDISSHRTARDISSHRTARDISSERTARDISSERTARDISSHRTARDISSERTARDIS

IARDISSERTARDISSERTARDISSERTARDISSERTARDISSERTARDISSERTARD HRTARDISSERTARDISSERTARDISSERTARDISSERTARDISSERTARDISSERTA SSERTARDISSERTARDISSERTARDISSERTARDISSERTARDISSERTARDISSER RDISSERTARDISSERTARDISSERTARDISSERTARDISSERTARDISSERTARDIS IARDISSERTARDISSERTARDISSERTARDISSERTARDISSERTARDISSERTARD HRTARDISSERTARDISSERTARDISSERTARDISSERTARDISSERTARDISSERTA SSERTARDISSERTARDISSERTARDISSERTARDISSERTARDISSERTARDISSER RDISSERTARDISSERTARDISSERTARDISSERTARDISSERTARDISSERTARDIS IARDISSERTARDISSERTARDISSERTARDISSERTARDISSERTARDISSERTARD HRTARDISSERTARDISSERTARDISSERTARDISSERTARDISSERTARDISSERTA SSERTARDISSERTARDISSERTARDISSERTARDISSERTARDISSERTARDISSER RDISSERTARDISSERTARDISSERTARDISSERTARDISSERTARDISSERTARDISE IARDISSERTARDISSERTARDISSERTARDISSERTARDISSERTARDISSERTARD HRTARDISSERTARDISSERTARDISSERTARDISSERTARDISSERTARDISSERTA SSERTARDISSERTARDISSERTARDISSERTARDISSERTARDISSERTARDISSER RDISSERTARDISSERTARDISSERTARDISSERTARDISSERTARDISSERTARDISC TARDISSERTARDISSERTARDISSERTARDISSERTARDISSERTARDISSERTARD RTARDISSERTARDISSERTARDISSERTARDISSERTARDISSERTARDISSERTA SSERTARDISSERTARDISSERTARDISSERTARDISSERTARDISSERTARDISSER RDISSERTARDISSERTARDISSERTARDISSERTARDISSERTARDISSERTARDIS IARDISSERTARDISSERTARDISSERTARDISSERTARDISSERTARDISSERTARD HRTARDISSERTARDISSERTARDISSERTARDISSERTARDISSERTARDISSERTA ISSERTARDISSERTARDISSERTARDISSERTARDISSERTARDISSERTARDISSER RDISSERTARDISSERTARDISSERTARDISSERTARDISSERTARDISSERTARDISE TARDISSERTARDISSERTARDISSERTARDISSERTARDISSERTARDISSERTARD HRTARDISSERTARDISSERTARDISSERTARDISSERTARDISSERTARDISSERTA ISSERTARDISSERTARDISSERTARDISSERTARDISSERTARDISSERTARDISSER RDISSERTARDISSERTARDISSERTARDISSERTARDISSERTARDISSERTARDIS TARDISSERTARDISSERTARDISSERTARDISSERTARDISSERTARDISSERTARD HRTARDISSERTARDISSERTARDISSERTARDISSERTARDISSERTARDISSERTA SSERTARDISSERTARDISSERTARDISSERTARDISSERTARDISSERTARDISSER RDISSERTARDISSERTARDISSERTARDISSERTARDISSERTARDISSERTARDIS TARDISSERTARDISSERTARDISSERTARDISSERTARDISSERTARDISSERTARD HRTARDISSERTARDISSERTARDISSERTARDISSERTARDISSERTARDISSERTA SSERTARDISSERTARDISSERTARDISSERTARDISSERTARDISSERTARDISSER RDISSERTARDISSERTARDISSERTARDISSERTARDISSERTARDISSERTARDISE IARDISSERTARDISSERTARDISSERTARDISSERTARDISSERTARDISSERTARD HRTARDISSERTARDISSERTARDISSERTARDISSERTARDISSERTARDISSERTA SSERTARDISSERTARDISSERTARDISSERTARDISSERTARDISSERTARDISSER RDISSERTARDISSERTARDISSERTARDISSERTARDISSERTARDISSERTARDISE IARDISSERTARDISSERTARDISSERTARDISSERTARDISSERTARDISSERTARD HRTARDISSERTARDISSERTARRTARDISSERTARDISSERTARDISSERTARDISS IARDISSERTARDISSERTARDISSERTARDISSERTARDISSERTARRTARDISSER RDISSERTARDISSERTARDISSERTARDISSERTARDISSERTARDISSERTARDIS 